\title{
Order Allocation and Purchasing Transportation Planning in the Garment Supply Chain: A Goal-Flexible Planning Approach
}

\author{
Roy Setiawan* \\ Universitas Kristen Petra, Surabaya, Indonesia
}

(Received: February 27, 2021 / Revised: April 2, 2021; April 12, 2021 / Accepted: April 19, 2021)

\begin{abstract}
The garment supply chain is one of the most common supply chains in the world. In this supply chain, quality and cost are the most important factors that are strongly related to the selection of suppliers and the allocation of orders to them. Accordingly, the purpose of this paper is to integrate decisions for supplier selection, order allocation, and multi-source, multi-mode, multi-product shipping plans with consideration of discounts under uncertainty. For this purpose, a multi-objective mixed-integer mathematical model is presented, including the objectives of minimizing costs and products with delays and maximizing the total purchase value. In this mathematical model, the policy of purchasing materials and determining the number and type of transport equipment are specified. To solve this mathematical model, a goal-flexible programming approach with a utility function is presented. In the solution algorithm, a new possibility-flexible programming method has been developed to deal with the uncertainties in the model, which is based on the expected value method and chance constraint. Finally, using a numerical problem, the establishment of the above model in the garment supply chain is investigated. As indicated by the outcomes, the proposed model was touchy to certain boundaries, including blended leaders' mentality, a boundary identified with fluffy imperatives, and the degree of certainty characterized by the chief for not exactly equivalent limitations.
\end{abstract}

Keywords: Garment Supply Chain, Order Allocation, Purchase Value, Goal Programming, Possibility-Flexible Planning

*Corresponding Author, E-mail: roy@petra.ac.id, sadlah.hmd@yahoo.com

\section{INTRODUCTION}

Supplier selection is a strategic process that determines the long-term survival of a company and plays a key role in achieving the competitive goals of a supply chain (Chan et al., 2008; Hammami et al., 2014). The share of purchase costs in the price of goods is about $60 \%$ in some industries and choosing suppliers and purchase planning are considerably important in reducing costs (Ballou, 2004). Among the globalized industries, attention has been paid to the garment industry both in terms of participating components and in terms of the complexity of the chain. On the other hand, most companies seek to produce high-quality products at a low cost, and the activities in the garment industry are related to the humanmachine system. Therefore, the wages of human resources are a large part of production costs. Since salary rates are often lower in developing countries, clothing products can be produced in other countries at lower costs, which is a reason for the increased importance of global resources in the garment industry (Su et al., 2005). The purchasing process along with other logistic decisions, such as determining the type and number of vehicles for the relocation of purchased items, lead to the integration 
of physical supply channel decisions. Since the transportation cost is often separate from the purchasing cost, the number and cost of means of transportation are important due to the limited capacity of vehicles. The importance of this issue increases when suppliers stimulate order levels as well by offering discounts. Therefore, integration of transportation decision-making and delivery modes along with other inbound logistic decisions for inventory management and order allocation help improve the supply chain performance.

The accurate estimation of the system's parameters is a difficult process in decisions related to plans for purchasing raw materials in the global supply chain. In this area, values such as transportation and purchasing costs, as well as demands and capacities are considered as definite default while they are naturally fuzzy and inaccurate. (Baghernejad and Fiuzat, 2021; Abdollahbeigi et al., 2020; Barmasi, 2020). As mentioned by Ghasemy Yaghin et al. (2015). There are also shortcomings in probabilistic and statistical models. For instance, a lack of correlation is assumed between the residuals in the popular and widely used method of least squares in estimating parameters, which is extremely limiting. This is significantly important in industries such as garment where adequate historical data does not exist for some of the new products. In addition, the theory of fuzzy sets is introduced as an alternative approach by considering intrinsic uncertainty (lack of data). Lack of attention to intrinsic uncertainty in important input of a logistic issue such as transportation costs and demand and applying management decisions as strict constraints without any deviations often leads to the poor performance of procurement planning in execution. In the modern world, order allocation and determining the amount of purchase have become significantly important considering the extensive competition and the existence of several sources of supply. Therefore, various articles have been prepared in this field, and an integrated model of distribution of fuzzy quality performance and multiobjective linear programming globally has been proposed by Kumar et al. (2011). In addition, Ghodsypour and O'Brien (2001), presented a non-linear programming model of complex integers to solve the multiple sourcing problem. In this regard, other researchers such as Demirtas and Üstün, (2008), Hamdan and Cheaitou (2016), Razmi et al. (2009), Kumar et al. (2004), and Keskin et al. (2010), have developed a model to solve the discussed issue. On the other hand, given the importance of transportation costs in the replenishment of the inventory and decisions of the supplier, various articles have presented models in this field (Pazhani et al., 2016; Songhori et al., 2011; Ghorbani et al., 2012; Díaz-Madroñero et al., 2014; Díaz-Madroñero et al., 2017).

Exchange-rate volatility is one of the controversial issues of buying abroad in the global supply chain literature. Therefore, Hu and Motwani (2013), proposed a model to minimize the risks of price reduction in relation to the supplier. In the same field, Hammami et al. (2014), proposed a mixed integer model based on the random planning method while considering exchange-rate volatility and discount price. In addition, other studies have focused on modeling in this area (Prasanna Venkatesan and Goh, 2016; Çebi and Otay, 2016). In another paper, Torabi and Torabi and Hassini (2009) presented a multiobjective model by considering multilevel production planning, purchase, and distribution programming in a multilevel supply chain network with several suppliers, multiple production plants, and multiple distribution centers in the automotive industry. Garment production companies have developed global sourcing not only for a competitive price but also for focusing on the key capabilities and productivity management in a competitive age. Global brands such as Gap (California, the United States), H\&M (Stockholm, Sweden), and Uniqlo (Yamaguchi, Japan) are examples of brands that have had successful domestic production without a context (Kim, 2012). The globalization of the garment industry was initiated when clothing companies of the United Stated moved their operations to Asia in search of cheaper production (Bonacich et al., 1994). In general, few articles have evaluated global resourcing changes and models, especially in the garment industry (Kim, 2012). In this research path in the field of the garment industry, some articles have only focused on the topic of supplier selection with a singlesource strategy and have overlooked order allocation worldwide (Teng and Jaramillo, 2005; Koprulu and Albayrakoglu, 2017; Baskaran et al., 2012). For instance, Adhikari et al. (2020) studied the garment supply chain under uncertainty of demand and proposed a risk-based mechanism. In addition, the effect of the wholesale price and retail price on garment supply chain efficiency has been assessed. Musau (2021) evaluated sustainability in the garment supply chain, where the chain value was analyzed based on economic, environmental, and social indexes. Accordingly, the purpose of this paper is to integrate decisions for supplier selection, order allocation, and multi-source, multi-mode, multi-product shipping plans with consideration of discounts under uncertainty.

In this regard, decisions related to purchasing raw materials and shipping schedule with multiple transportation modes at any discount level are considered in a fuzzy environment. With regard to the existing articles, the present study aimed to present a multi-objective mixed possibility-flexible programming approach in the field of the garment industry to fill the literature gap. Based on the available literature, limited articles have focused on global resourcing in the garment industry in the field of global purchasing, and most papers have analyzed purchasing decisions under certainty. Meanwhile, there is uncertainty in the area of decisions in the supply chain, and the main uncertainty is considered in the parameters 
existing in the model. In addition, despite multilevel discounts of simultaneous study of integrated purchasing and transportation decisions in a multi-product and multisource, there are a few articles available in this area. The remainder of this paper is structured as follows: section 2 provides problem definitions and assumptions, section 3 explains the mathematical model and solution algorithm, section 4 provides computational results in the garment industry and section 5 concludes.

\section{METHODOLOGY}

Consider a supply chain that faces a product supply planning issue and has attempted to make raw material purchasing decisions (e.g., textile), select purchasing resources, and plan the global transportation of products globally under uncertainty. On one hand, providing discounts by suppliers affects the amount of order and purchasing cost and can act as a competitive factor among the suppliers. There are various types of discounts, one of which depends on the total value of sales volume - not in the amount or type of purchased products - over a period. With the emergence of the concept of timely purchasing, suppliers concluded that discounts were significant based on the total value of orders of several products (i.e., total business volume) that are ordered by a buyer (Xia and $\mathrm{Wu}, 2007)$. In addition, different types of transportation modes with various volumes and different volumes of items to be ordered affect the number of means of transportation for shipping of products and their transportation costs, especially at the global level. Decisions about the type and number of means of transportation that are simultaneously made with order allocation prevent addi-

Table 1. Mathematical model information

\begin{tabular}{|c|c|c|}
\hline Type & Variable & Descriptions of variables \\
\hline \multirow{5}{*}{ Indexes } & $g=1 \ldots \ldots G$ & Index related to the type of mode of transport \\
\hline & $j=1 \ldots . . . \mathrm{J}$ & Index related to the type of products (textile) \\
\hline & $i=1 \ldots . . I$ & Index related to suppliers (textile weaving units) \\
\hline & $k=1 \ldots . . K$ & Index related to objective functions \\
\hline & $l=1 \ldots . L$ & Index related to less-than-or-equal fuzzy constraints \\
\hline \multirow{22}{*}{ Parameters } & $\tilde{p}_{i j}$ & Unit price (square meters) of $\mathrm{j}$-th product (textile) from the $\mathrm{i}$-th weaving unit in fuzzy environment \\
\hline & $\tilde{L}_{i j g}$ & Percentage of product $\mathrm{j}$ delivered late by the $\mathrm{i}$-th weaving unit by the $\mathrm{g}$-th mode in fuzzy environment \\
\hline & $C C_{i}$ & The score of the i-th weaving unit \\
\hline & $\tilde{N}_{j}$ & Total purchase of the $\mathrm{j}$-th product from weaving units in fuzzy environment (in $\mathrm{m}^{2}$ ) \\
\hline & $\overline{\tilde{S}_{i j}}$ & The capacity of the $\mathrm{i}$-th weaving unit for the $\mathrm{j}$-th product in fuzzy environment $\left(\mathrm{m}^{2}\right)$ \\
\hline & $f_{k, \min }$ & The minimum level of satisfaction of the k-th objective function \\
\hline & $f_{k . \max }$ & The maximum level of satisfaction of the k-th objective function \\
\hline & $\begin{array}{c}\tilde{w}_{k}^{d} \\
\end{array}$ & Importance of the k-th objective function in fuzzy environment \\
\hline & $\tilde{w}_{k}^{\delta}$ & Weight related to $\delta_{k}^{-}$in fuzzy environment \\
\hline & $R_{i}$ & Range of discounts of the i-th weaving unit \\
\hline & $m_{i}$ & The number of discount levels in the discount program of the i-th weaving unit \\
\hline & $r$ & Discount level $\left(\mathrm{rm}_{\mathrm{i}} \leq \leq 1\right)$ \\
\hline & $\tilde{d}_{i r}$ & $\begin{array}{l}\text { Discount coefficient related to the r-th level in the discount program of the } \mathrm{i} \text {-th weaving unit in fuzzy } \\
\text { environment (in percentage) }\end{array}$ \\
\hline & $b_{i r}$ & High limit at the r-th level in the discount program of the i-th weaving unit \\
\hline & $\tilde{O}_{i j}$ & $\begin{array}{l}\text { The mean number of damages in a bolt }\left(90 \mathrm{~m}^{2}\right) \text { of textile type } \mathrm{j} \text { from the } \mathrm{i} \text {-th weaving unit in a fuzzy } \\
\text { environment }\end{array}$ \\
\hline & $O S_{i j}$ & The maximum number of damages in the textile type $\mathrm{j}$ at the $\mathrm{i}$-th weaving unit in each bolt \\
\hline & $V C_{g}$ & The rate of transportation cost for the g-th mode \\
\hline & $d d_{i g}$ & Distance from the i-th weaving unit to the buyer with the g-th mode $(\mathrm{km})$ \\
\hline & $v_{j}$ & The amount of fabric in the bolt of the textile type $\mathrm{j}\left(\mathrm{in} \mathrm{m}^{3} \mathrm{or}_{\mathrm{cm}}^{3}\right.$ ) \\
\hline & $V T_{g}$ & Volume (capacity) of the g-th mode in $\left(\mathrm{m}^{3}\right.$ or $\left.\mathrm{cm}^{3}\right)$ \\
\hline & $\tilde{T} C_{i}$ & $\begin{array}{l}\text { The maximum cost of transportation from the i-th weaving unit in the fuzzy environment (determined } \\
\text { by the manufacturer) }\end{array}$ \\
\hline & $f_{k}(x)$ & The k-th linear objective function \\
\hline
\end{tabular}


Table 1. Mathematical model information (Continued)

\begin{tabular}{|c|c|c|}
\hline \multirow{13}{*}{$\begin{array}{l}\text { Decision- } \\
\text { making } \\
\text { variables }\end{array}$} & $g_{k}$ & Satisfaction level/target of the k-th objective function \\
\hline & $g_{l m}$ & The satisfaction level/target $\mathrm{m}$ of the $\mathrm{k}$-th objective function \\
\hline & $\beta$ & The probability of fuzzy equality constraint \\
\hline & $\varepsilon$ & The optimistic-pessimistic parameter to determine the mixed decision-makers' attitude \\
\hline & E & The level of confidence defined by the decision-maker to satisfy greater-than-or-equal fuzzy constraints \\
\hline & $\Gamma$ & The level of confidence defined by the decision-maker to satisfy less-than-or-equal fuzzy constraints \\
\hline & $\alpha$ & $\begin{array}{l}\text { Fuzzy parameter related to fuzzy constraints (in the method of flexible programming for unequal } \\
\text { constraints) }\end{array}$ \\
\hline & $\mathrm{d}$ & The amount exceeding the value on the right of each less-than-or-equal fuzzy constraint \\
\hline & $x i j$ & The rate of the order of the textile type $\mathrm{j}$ in $\mathrm{m}^{2}$ to the $\mathrm{i}$-th weaving unit $\left(\mathrm{m}^{2}\right)$ \\
\hline & $V_{i r}$ & The volume (amount) of business (commercial) purchased from the i-th weaving unit at the r-th level \\
\hline & $u_{i r}$ & $\begin{array}{l}\text { The binary variable is equal to one in case of the volume of the business purchased from the } \mathrm{i} \text {-th } \\
\text { weaving unit at the } \mathrm{r} \text {-th discount level } \mathrm{n}_{\mathrm{ig}} \text { the number of means of transportation of the g-th mode } \\
\text { from the } \mathrm{i} \text {-th weaving unit }\end{array}$ \\
\hline & $Q_{i j g}$ & $\begin{array}{l}\text { The amount of delivery of the textile type } \mathrm{j}\left(\text { in }^{2} \mathrm{~m}^{2} \text { ) to the } \mathrm{i} \text {-th weaving unit with the transportation }\right. \\
\text { mode } \mathrm{g}\left(\mathrm{m}^{2}\right)\end{array}$ \\
\hline & $\mathrm{h}_{\mathrm{ig}}$ & The binary variable will be equal to one if the order is transferred from the $\mathrm{i}$-th weaving unit by the mode $g$ \\
\hline \multirow{4}{*}{ Covariates } & $y_{k}$ & Continuous decision variable related to the k-th objective function (covariate for solving ideal planning) \\
\hline & $\mathrm{d}_{\mathrm{k}}^{+}$ & The upper limit (positive deviation) of the k-th target \\
\hline & $\mathrm{d}_{\mathrm{k}}^{-}$ & The lower limit (positive deviation) of the k-th target \\
\hline & $\lambda_{k}$ & The value of the utility for the k-th objective function \\
\hline
\end{tabular}

tional transportation costs and lead to determining the required number of means of transportation proportional to the number of purchases per period. Ultimately, the central organization seeks to determine the following programs in an integrated manner in a multi-objective environment:

- Raw material purchasing program: includes deciding about purchasing source determination and purchasing volume at any discount level offered by potential suppliers.

- Transportation program: includes deciding about the number of means of transportation required for each transportation mode. In fact, this program specifies that each supplier, if selected, will ship the goods by how long and how many means of transportation.

The symbols and parameters used for modeling are presented in the table below.

A hypothesis was considered for modeling the problem, which included the number of purchases from each source, taking into account the capacity of suppliers, is limited to the total amount of purchases from sources and the capacity of means of transportation. In addition, an upper limit is considered for the total damages in purchased textile given the important role of fabric quality in the final product. In addition, the percentage of delayed products is considered for each supplier based on their background. There is a predetermined set of potential suppliers, and a multi-level discount program is proposed by the suppliers. In other words, the discount percentage increases with increased total purchase volume. Moreover, all suppliers offer one type of discount (business volume discount with similar discount levels). The purchasing company is not responsible for the delivery of products. Therefore, the buyer only pays the variable cost based on "distance". Furthermore, there are various modes of transportation for delivering the purchased items to buyers by suppliers. Symmetric triangular fuzzy numbers are used to model uncertainty in parameters.

In this section, we first developed a multi-objective mathematical model. We considered three objective functions (equations one-three) including maximizing the total purchase value $\left(f_{1}\right)$, minimizing the logistic costs including purchasing and transportation $\left(\mathrm{f}_{2}\right)$, and minimizing delayed deliveries $\left(\mathrm{f}_{3}\right)$.

$$
\begin{array}{ll}
f_{1}(x)=\sum_{j=1}^{J} \sum_{i=1}^{I} c c_{i} x_{i j} & \\
f_{2}(x)=\sum_{i=1}^{I} \sum_{r \in R_{i}}\left(1-\tilde{d}_{i r}\right) V_{i r}+\sum_{i=1}^{I} \sum_{g=1}^{G} V C_{g} \times d d_{i g} \times n_{i g} \\
f_{3}(x)=\sum_{j=1}^{J} \sum_{i=1}^{I} \tilde{L}_{i j} x_{i j} & \forall j \\
\sum_{i=1}^{I} x_{i j}=\tilde{N}_{j} & \forall i, j \\
x_{i j} \leq \tilde{S}_{i j} &
\end{array}
$$




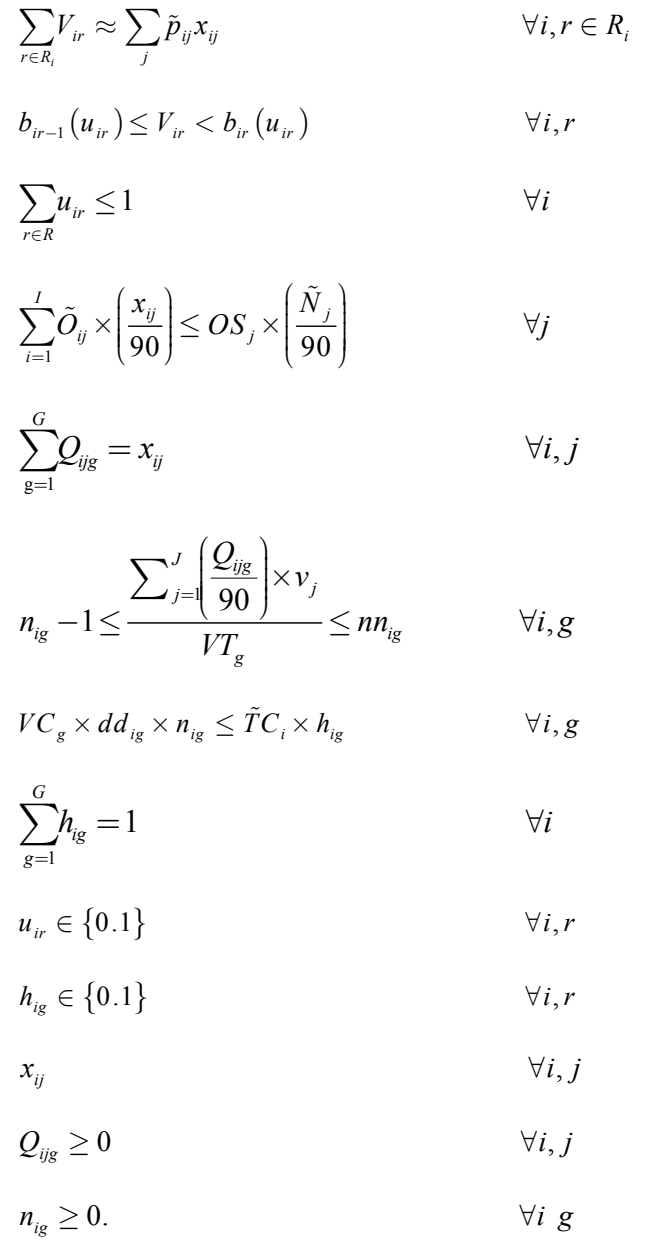

In the mentioned constraints, constraint ( $\mathrm{Su}$ et al., 2005) was related to the corporation's purchasing policy, in a way that the total number of orders made by suppliers for a product is equal to a specific amount. Constraint (5) was related to the capacity of each supplier, and constraint (6) showed the total business volume purchased from each supplier. In addition, constraint (7) claims that in order to use the discount on a purchase from the supplier, the volume of the purchased business should be greaterthan-or-equal to the maximum business volume at the previous discount level and smaller than the maximum business volume at the current discount level. Constraint (8) guarantees that purchasing can be made only at one of the discount levels presented by the supplier. Constraint (9) is related to the number of damages in each bolt of textile. Since each bolt is considered to contain $90 \mathrm{~m}^{2}$ of textile, the number of orders is divided by 90 to obtain the number of $90-\mathrm{m}^{2}$ bolts. In addition, constraint (10) shows the relationship between the delivered amount with the transportation mode and the amount of order from each resource. Constraint (11) is related to the number of means of transportation from each mode of transport and each supplier. Moreover, constraints (12) and (13) are related to the transportation cost of each mode. In fact, a maximum transportation cost is considered for each sup- plier. Ultimately, constraints (14) and (15) are related to the binary variable, whereas constraints (16) and (17) are related to non-negative variables, and constraint (18) is related to the integer variable.

\section{RESULTS AND DISCUSSION}

The developed model is a multi-objective model in the form of linear programming with integer variables. Chang (2011) has developed a new approach entitled "multi-choice goal programming with utility functions". Given the uncertainty at the objective/satisfaction level, it would be easier for the decision-maker to determine a range of objectives or satisfaction instead of a single-level target. In this model, the decision-maker seeks to achieve maximum utility. The ideal multi-choice planning with utility function is, as follows, where $w_{k}^{d}$ is the importance (weight) of the objective $\mathrm{k}$ and $\mathrm{w}_{\mathrm{k}}^{\delta}$ is the weight related to $\delta_{\mathrm{k}}^{-}$.

$$
\min \sum_{k=1}^{K}\left(w_{k}^{d}\left(d_{k}^{-}+d_{k}^{+}\right)+w_{k}^{\delta} \delta_{k}^{-}\right)
$$

s.t.

$$
\begin{array}{lc}
\lambda_{k} \leq \frac{f_{k, \max }-y_{k}}{f_{k, \max }-f_{k, \min }} & \forall k \\
f_{k}(x)+d_{k}^{-}+d_{k}^{+}=y_{k} & \forall \mathrm{k} \\
f_{k, \text { rin }} \leq y_{k} \leq f_{k \max } & \forall \mathrm{k} \\
\lambda_{k}+\delta_{k}=1 & \forall \mathrm{k} \\
d_{k}^{-} \cdot d_{k}^{+}=0 & \forall \mathrm{k} \\
d_{k} \cdot d_{k}^{+} \cdot \delta_{k}^{-} \cdot \lambda_{k} \geq 0 & \forall \mathrm{k}
\end{array}
$$

In the proposed model, constraints of (3-19) for the second and third functions and constraints of (4) and (6) are considered to be almost equal and fuzzy, which indicated their relative satisfaction. In addition, fuzzy parameters exist in constraints of (3-19) per the second and third objective functions. Moreover, the weights related to $\mathrm{d}+\mathrm{k}$, $\mathrm{d}-\mathrm{k}$ and $\delta-k$ could be considered as fuzzy since the decision-maker may not be able to express the significance of each objective function with an exact value. Therefore, due to the fuzzy nature of some mathematical parameters and symbols in the original model, it is necessary to first de-fuzzy the fuzzy mathematical parameters and symbols. Accordingly, the broad state of the fuzzy model of multiselective ideal programming with the utility function is expressed separately as follows. The body-wide fuzzy modeling of ideal multi-objective planning with utility function is expressed separately, as follows: 


$$
\left.\min \sum_{k=1}^{3} \tilde{w}_{k}^{d}\left(d_{k}^{-}+d_{k}^{+}\right)+\tilde{w}_{k}^{\delta} \delta_{k}^{-}\right)
$$

s.t.

$$
\begin{aligned}
& \left(-\sum_{j=1}^{J} \sum_{i=1}^{I} c c_{i} x_{i j}\right)+d_{1}^{-}+d_{1}^{+}=y_{1} \\
& \left(\sum_{i=1}^{I} \sum_{r \in R_{i}}\left(1-\tilde{d}_{i r}\right) V_{i r}+\sum_{i=1}^{I} \sum_{g=1}^{G} V C_{g} \times d d_{i g} \times n_{i g}\right) \\
& +d_{2}^{-}+d_{2}^{+}=y_{2} \\
& \left(\sum_{j=1}^{J} \sum_{i=1}^{I} \tilde{L}_{i j} x_{i j}\right)+d_{3}^{-}+d_{3}^{+}=y_{3}
\end{aligned}
$$

Given the uncertainty in mathematical symbols, the mathematical symbols must first be de-fuzzified, and the fuzzy parameters of the created model are de-fuzzified. In general, there are two types of fuzzy constraints: 1) equal fuzzy constraints and 2) non-equal constraints, for defuzzification of which a possibility-flexible programming approach has been developed.

In this article, we deal with constraints that both have fuzzy parameters and equality is established in a fuzzy manner. These constraints included (4), (6), (22), and (23). A defuzzification method of these constraints is using the method developed by Parra et al. (2005) Using the expected range, the fuzzy equality constraint encompassing fuzzy parameters is turned into two definite constraints. If is assumed as a triangular fuzzy number $a=\left(a^{L}, a^{c}, a^{R}\right)$, its expected range will be, as follows:

$$
E I[\tilde{a}]=\left[E I(\tilde{a})^{L}, \operatorname{EI}(\tilde{a})^{R}\right]=\left[\frac{a^{L}+a^{C}}{2}, \frac{a^{C}+a^{R}}{2}\right]
$$

Therefore, using the model of Parra et al. (2005) the fuzzy equality constraints of (4), (6), (22), and (23) will be defuzzied, as followed:

$$
\begin{aligned}
& \left(\sum_{i=1}^{I} \sum_{r \in R_{i}}\left(1-\left[\left(1-\frac{\beta}{2}\right) E I\left(\tilde{d}_{i r}\right)^{L}+\left(\frac{\beta}{2}\right) E I\left(\tilde{d}_{i r}\right)^{R}\right]\right) V_{i r}\right. \\
& \left.+\sum_{i=1}^{I} \sum_{g=1}^{G} V C_{g} \times d d_{i g} \times n_{i g}\right)+d_{2}^{-}+d_{2}^{+} \leq y_{2} \\
& (Y \xi)\left(\sum_{i=1}^{I} \sum_{r \in R_{i}}\left(1-\left[\left(\frac{\beta}{2}\right) E I\left(\tilde{d}_{i r}\right)^{L}+\left(1-\frac{\beta}{2}\right) E I\left(\tilde{d}_{i r}\right)^{R}\right]\right) V_{i r}\right. \\
& \left.+\sum_{i=1}^{I} \sum_{g=1}^{G} V C_{g} \times d d_{i g} \times n_{i g}\right)+d_{2}^{-}+d_{2}^{+} \geq y_{2} \\
& \left.\left(\sum_{j=1}^{J} \sum_{i=1}^{I}\left[\left(1-\frac{\beta}{2}\right) E I(\tilde{L})^{L}+\left(\frac{\beta}{2}\right) E I(\tilde{L})^{R}\right]\right]_{i j} x_{i j}\right) \\
& +d_{3}^{-}+d_{3}^{+} \leq y_{3}
\end{aligned}
$$

$$
\begin{gathered}
\left(\sum_{j=1}^{J} \sum_{i=1}^{I}\left[\left(\frac{\beta}{2}\right) E I\left(\tilde{L}_{i j}\right)^{L}+\left(1-\frac{\beta}{2}\right) E I\left(\tilde{L}_{i j}\right)^{R}\right] x_{i j}\right) \\
+d_{3}^{-}+d_{3}^{+} \geq y_{3} \\
\sum_{i=1}^{I} x_{i j} \geq\left[\left(1-\frac{\beta}{2}\right) E I\left(\tilde{N}_{j}\right)^{L}+\left(\frac{\beta}{2}\right) E I\left(\tilde{N}_{j}\right)^{R}\right] \\
\sum_{i=1}^{I} x_{i j} \leq\left[\left(\frac{\beta}{2}\right) E I\left(\tilde{N}_{j}\right)^{L}+\left(1-\frac{\beta}{2}\right) E I\left(\tilde{N}_{j}\right)^{R}\right] \forall j \\
\sum_{r \in R_{i}} V_{i r} \geq \sum_{j}\left[\left(1-\frac{\beta}{2}\right) E I\left(\tilde{p}_{j i}\right)^{L}+\left(\frac{\beta}{2}\right) E I\left(\tilde{p}_{j i}\right)^{R}\right] x_{i j} \\
\forall i . r \in R_{i} \\
\sum_{r \in R_{i}} V_{i j} \leq \sum_{j}\left[\left(\frac{\beta}{2}\right) E I\left(\tilde{p}_{j i}\right)^{L}+\left(1-\frac{\beta}{2}\right) E I\left(\tilde{p}_{j i}\right)^{R}\right] x_{i j} \\
\forall i . r \in R_{i}
\end{gathered}
$$

In the proposed model, some unequal constraints are considered flexible (fuzzy inequality), which are mentioned below:

$$
\begin{aligned}
& \lambda_{k} \tilde{\leq} \frac{f_{k, \text { max }}-y_{k}}{f_{k, \text { max }}-f_{k, \text { min }}} \text { for } k=1.2 .3 \\
& f_{k, \text { min }} \tilde{\leq} y_{k} \tilde{\leq} f_{k, \text { max }} \text { for } k=1.2 .3 \\
& x_{i j} \leq \tilde{S}_{i j}
\end{aligned}
$$

Various methods have been proposed to deal with this group of constraints, one of which is the technique by Cadenas and Verdegay (1997), which was previously applied in the article (Ghasemy Yaghin et al., 2013). In this method, a value for allowed violation from the right is considered the desired limit. According to Cadenas and Verdegay (1997), if a mathematical planning model exists with the following constraints, the constraint with a fuzzy symbol can be replaced by the constraint presented below (right side).

$$
\begin{array}{ll}
\sum_{i} a_{i j} x_{i} \leq_{g} b_{i}+d_{i}(1-\alpha) & \forall j \in M \\
\sum_{i} a_{i j} x_{i} \tilde{\leq} b_{i} & \forall j \in M=\{1 \ldots \ldots m\}
\end{array}
$$

On the other hand, since some constraints existing in the proposed model have fuzzy parameters on their right side, the desired constraint will be as follows using (Zhalechian et al., 2017).

$$
\sum_{i} \tilde{a}_{i j} x_{i} \tilde{\leq} \tilde{b}_{i} \Rightarrow \sum_{i} \tilde{a}_{i j} x_{i} \leq_{g} \tilde{b}_{i} \oplus \tilde{d}_{i}+(1-\alpha) \quad \forall j \in M
$$

According to the equation above, the symbol of $\mathrm{g} \leq$ is related to the $\mathrm{g}$ linear ranking function. Based on Cadenas and Verdegay (1997) it is proven that fuzzy in- 
equality constraint is turned into the right-side constraint in equitation (37) and is defuzzied. More descriptions on the matter are presented in articles (Ghasemy Yaghin et al., 2013) and (Zhalechian et al., 2017). Therefore, the fuzzy inequality constraints are defuzzied based on the proposed model.

$$
\begin{aligned}
& \lambda_{1} \leq\left(\frac{f_{1, \text { max }}-y_{1}}{f_{1, \text { max }}-f_{1, \text { min }}}\right)+\mathrm{d}_{1}^{1}(1-\alpha) \\
& \lambda_{2} \leq\left(\frac{f_{2, \text { max }}-y_{2}}{f_{2, \text { max }}-f_{2, \text { min }}}\right)+\mathrm{d}_{2}^{1}(1-\alpha) \\
& \lambda_{3} \leq\left(\frac{f_{3, \text { max }}-y_{3}}{f_{3, \text { max }}-f_{3, \text { min }}}\right)+\mathrm{d}_{3}^{1}(1-\alpha) \\
& y_{1} \leq f_{1, \text { max }}+\mathrm{d}_{1}^{3}(1-\alpha) \cdot f_{1, \text { min }} \leq y_{1}+\mathrm{d}_{1}^{2}(1-\alpha) \\
& y_{2} \leq f_{2, \text { max }}+\mathrm{d}_{2}^{3}(1-\alpha) \cdot f_{2, \text { min }} \leq y_{2}+\mathrm{d}_{2}^{2}(1-\alpha) \\
& y_{3} \leq f_{3, \text { max }}+\mathrm{d}_{3}^{3}(1-\alpha) \cdot f_{3, \text { min }} \leq y_{3}+\mathrm{d}_{3}^{2}(1-\alpha) \\
& x_{i j} \leq \tilde{S}_{i j}+\tilde{d}^{4}(1-\alpha)
\end{aligned}
$$

There are various methods to turn fuzzy models into non-fuzzy models in the fuzzy planning literature. Meanwhile, the chance-constrained probabilistic programming method is the most applied technique due to enabling decision-makers to control the satisfaction level of constraints. Moreover, several fuzzy values have been presented to turn fuzzy constraint into its equivalent definitive constraint. In this research path (Ghasemy Yaghin et al., 2013). First presented a new fuzzy value named "Me", followed by proposing a technique to turn the fuzzy model into the definitive model using the Me value in the expectation and chance-constrained model. The main advantage of this method is having more flexibility regarding the prevention of severe and different attitudes of decision-makers. This is mainly because decision-makers often have different optimistic and pessimistic attitudes in handling real situations. In other words, the mixed decision-makers' attitude is considered, which is something between optimistic and pessimistic (Ghasemy Yaghin et al., 2013). If $\xi$ is assumed as a triangular fuzzy parameter $\xi=\left(\xi_{1} \cdot \xi_{2} \cdot \xi_{3}\right)$, the expectation value is obtained, as follows:

$$
E[\xi]=\frac{1-\varepsilon}{2} \xi_{1}+\frac{1}{2} \xi_{2}+\frac{3}{2} \xi_{3}
$$

According to $\mathrm{Xu}$ and Zhou's definition, the expectation and chance-constrained model in definitive mode can be turned into two approximate models with upper approximation model (UAM) and lower approximation model (LAM) (Ghasemy Yaghin et al., 2013). According to the model developed by $\mathrm{Xu}$ and $\mathrm{Zhou}$, the following shows the body-wide definitive model for multi-choice ideal planning with fuzzy-utility function, which is pre- sented in section 2-4, for the UAM model:

$$
\begin{aligned}
& \min U A M: \sum_{k=1}^{3}\left(\tilde{w}_{k}^{d}\left(d^{-}+d^{+}\right)+\tilde{w}_{k}^{\delta} \delta^{-}\right) \\
& =\left[\left(\frac{1-\varepsilon}{2} w_{1(1)}^{d}+\frac{1}{2} w_{1(2)}^{d}+\frac{\varepsilon}{2} w_{1(3)}^{d}\right) \times\left(d^{-}+d_{1}^{+}\right)\right. \\
& \left.+\left(\frac{1-\varepsilon}{2} w_{1(1)}^{\delta}+\frac{1}{2} w_{1(2)}^{\delta}+\frac{\varepsilon}{2} w_{1(3)}^{\delta}\right) \times\left(\delta_{1}^{-}\right)\right] \\
& +\left[\left(\frac{1-\varepsilon}{2} w_{2(1)}^{d}+\frac{1}{2} w_{2(2)}^{d}+\frac{\varepsilon}{2} w_{2(3)}^{d}\right)\right. \\
& \times\left(d^{-}+d_{2}^{+}\right)+\left(\frac{1-\varepsilon}{2} w_{2(1)}^{\delta}+\frac{1}{2} w_{2(2)}^{\delta}+\frac{\varepsilon}{2} w_{2(3)}^{\delta}\right) \\
& \left.\times\left(\delta_{2}^{-}\right)\right]+\left[\left(\frac{1-\varepsilon}{2} w_{3(1)}^{d}+\frac{1}{2} w_{3(2)}^{d}+\frac{\varepsilon}{2} w_{3(3)}^{d}\right)\right. \\
& \left.\times\left(d_{3}^{-}+d_{3}^{+}\right)+\left(\frac{1-\varepsilon}{2} w_{3(1)}^{\delta}+\frac{1}{2} w_{3(2)}^{\delta}+\frac{\varepsilon}{2} w_{3(3)}^{\delta}\right) \times\left(\delta^{-}\right)\right] \\
& x_{i j} \leq \tilde{S}_{i j}+\tilde{d}^{4}(1-\alpha):\left\{\begin{array}{c}
\tilde{S}_{i j}=\left(S_{i j}^{1} \cdot S_{i j}^{2} \cdot S_{i j}^{3}\right) \\
\tilde{d}^{4}=\left(\mathrm{d}_{1}^{4} \cdot \mathrm{d}_{2}^{4} \cdot \mathrm{d}_{3}^{4}\right) \\
(1-\alpha)=A A
\end{array}\right\} \\
& \Rightarrow x_{i j} \leq\left(S_{i j}^{2}+\mathrm{d}_{2}^{4}(A A)\right)+(1-\gamma) \\
& \left(\left(S_{i j}^{3}+d_{3}^{4}(A A)\right)-\left(S_{i j}^{2}+\mathrm{d}_{2}^{4}(A A)\right)\right) \\
& \sum_{i=1}^{I} \tilde{O}_{i j} \times\left(\frac{x_{i j}}{90}\right) \leq O S_{j} \times\left(\frac{\tilde{N}_{j}}{90}\right) \\
& \Rightarrow \sum_{i=1}^{I}\left(O_{i j}^{2}-(1-\gamma)\left(O_{i j}^{2}-O_{i j}^{1}\right)\right) \\
& \times\left(\frac{x_{i j}}{90}\right) \leq O S_{j} \times\left(\frac{\left(N_{j}^{2}\right)+(1-\gamma)\left(N_{j}^{3}-N_{j}^{2}\right)}{90}\right) \\
& V C_{g} \times d d_{i g} \times n_{i g} \leq \tilde{T} C_{i} \times h_{i g} \Rightarrow V C_{g} \times d d_{i g} \times n_{i g} \leq h_{i g} \\
& \times\left[\left(T C_{j i}^{2}\right)+(1-\gamma)\left(T C_{j i}^{3}-T C_{j i}^{2}\right)\right]
\end{aligned}
$$

Other constraints: (7-8), (10-11), (13-18), (19-5) to (19-7), (21), (25)-(32) and (38)-(46). In addition, a process similar to that of the UAM is carried out to develop the definitive LAM, as shown below:

$$
\begin{aligned}
\min L A M: & \sum_{k=1}^{3}\left(\tilde{w}_{k}^{d}\left(d_{k}^{-}+d_{k}^{+}\right)+\tilde{w}_{k}^{\delta} \delta_{k}^{-}\right)= \\
& {\left[\left(\frac{1-\varepsilon}{2} w_{1(1)}^{d}+\frac{1}{2} w_{1(2)}^{d}+\frac{\varepsilon}{2} w_{1(3)}^{d}\right)\right.} \\
& \left.\times\left(d^{-}+d^{+}\right)+\left(\frac{1-\varepsilon}{2} w_{1(1)}^{\delta}+\frac{1}{2} w_{1(2)}^{\delta}+\frac{\varepsilon}{2} w_{1(3)}^{\delta}\right) \times\left(\delta_{1}^{-}\right)\right] \\
& +\left[\left(\frac{1-\varepsilon}{2} w_{2(1)}^{d}+\frac{1}{2} w_{2(2)}^{d}+\frac{\varepsilon}{2} w_{2(3)}^{d}\right)\right. \\
& \left.\times\left(d^{-}+d_{2}^{+}\right)+\left(\frac{1-\varepsilon}{2} w_{2(1)}^{\delta}+\frac{1}{2} w_{2(2)}^{\delta}+\frac{\varepsilon}{2} w_{2(3)}^{\delta}\right)\right]
\end{aligned}
$$




$$
\begin{aligned}
& \left.\times\left(\delta^{-}{ }_{2}\right)\right]+\left[\left(\frac{1-\varepsilon}{2} w_{3(1)}^{d}+\frac{1}{2} w_{3(2)}^{d}+\frac{\varepsilon}{2} w_{3(3)}^{d}\right)\right. \\
& \left.\times\left(d^{-}+d^{+}\right)+\left(\frac{1-\varepsilon}{2} w_{3(1)}^{\delta}+\frac{1}{2} w_{3(2)}^{\delta}+\frac{\varepsilon}{2} w_{3(3)}^{\delta}\right) \times\left(\delta_{3}^{-}\right)\right] \\
& \text {s.t. } \\
& \sum_{i=1}^{I} \tilde{O}_{i j} \times\left(\frac{x_{i j}}{90}\right) \leq O S_{j} \times\left(\frac{\tilde{N}_{j}}{90}\right) \\
& \Rightarrow \sum_{i=1}^{I}\left(O_{i j}^{2}+(1-\gamma)\left(O_{i j}^{3}-O_{i j}^{2}\right)\right) \times\left(\frac{x_{i j}}{90}\right) \leq O S_{j} \\
& \times\left(\frac{\left(N_{j}^{2}\right)-(\gamma)\left(N_{j}^{2}-N_{j}^{1}\right)}{90}\right) \\
& V C_{g} \times d d_{i g} \times n_{i g} \leq T C_{i} \times h_{i g} \Rightarrow V C_{g} \times d d_{i g} \\
& \times n_{i g} \leq h_{i g} \times\left[\left(T C_{j i}^{2}\right)-(\gamma)\left(T C_{j i}^{2}-T C_{j i}^{1}\right)\right] \\
& x_{i j} \leq \tilde{S}_{i j}+\tilde{d}^{4}(1-\alpha): i f\left\{\begin{array}{c}
\tilde{S}_{i j}=\left(S_{i j}^{1} \cdot S_{i j}^{2} \cdot S_{i j}^{3}\right) \\
\tilde{d}^{4}=\left(\begin{array}{cc}
4 & 4 \\
1 & 2 \\
2 & 4 \\
3
\end{array}\right) \\
(1-\alpha)=A A
\end{array}\right\} . \\
& \Rightarrow x_{i j} \leq\left(S_{i j}^{2}+\mathrm{d}_{2}^{4}(A A)\right) \\
& -(\gamma)\left(\left(S_{i j}^{2}+d_{2}^{4}(A A)\right)\right) \\
& \left.-\left(S_{i j}^{1}+\mathrm{d}_{1}^{4}(A A)\right)\right)
\end{aligned}
$$

Other constraints: (7), (8), (10), (11), (13)-(18), (19-5) to (19-7), (21), (25)-(32) and (38)-(46).

According to research, the primary objective for the participation of companies is to attain competitive advantage, the main solution of which is global sourcing. However, this concept is increasingly evolving in the world. In the garment industry, textile production and clothing manufacturing in the same place can be a complicated process for the management. Therefore, the use of foreign sources instead of a large production capacity in the pur- chasing country has become a norm in textile production. However, the main advantage of producing textile with foreign sources enables us to produce higher-quality clothes and choose better textile materials (Su et al., 2005; Nayak and Padhye, 2015).This section evaluates the topic of textile purchasing planning as a case study. It is notable that calculations were carried out in GAMS 25 and CPLEX software.

The hypotheses and parameters related to numerical example are presented below:

1. Six suppliers, two types of products and two transportation modes are considered.

2. The volume (capacity) of transportation modes 1 and 2 is considered $24.2 \mathrm{~m}^{3}$ and $25 \mathrm{~m}^{3}$, respectively.

3. The unit of transportation cost from the supplier to the buyer is in Tomans per kilometer.

4. The value of $w_{k}^{d}$ for each objective function is 0.8 and the value of $w_{k}^{\delta}$ for all three functions is 0.7 .

5. The four parameters of $\varepsilon, \alpha, \beta$, and $\gamma$ are considered to be $0.5,0.9,0.85$, and 0.75 , respectively.

6. Since the order is made in $\mathrm{m}^{2}$, the volume of each bolt of fabric is considered 0.012 and 0.013 for

\begin{tabular}{|c|c|c|c|c|c|c|c|c|}
\hline & Product(j) & $\begin{array}{c}\text { Order } \\
\text { Quantity }\left(\mathrm{m}^{2}\right)\end{array}$ & $\begin{array}{l}\text { Transportation } \\
\text { mode }\end{array}$ & $\begin{array}{c}\text { Number of } \\
\text { transportation } \\
\text { mode }\end{array}$ & $\begin{array}{c}\text { Variables of } \\
\text { model }\end{array}$ & Ob. 1 & Ob. 2 & Ob. 3 \\
\hline \multirow{2}{*}{1} & 1 & 38575.468 & \multirow{2}{*}{1} & \multirow{2}{*}{2} & \multirow{2}{*}{$d^{-}$} & \multirow{2}{*}{0} & \multirow{2}{*}{0} & \multirow{2}{*}{0} \\
\hline & 2 & 203525 & & & & & & \\
\hline \multirow{2}{*}{2} & 1 & - & & & \multirow{2}{*}{$d^{+}$} & \multirow{2}{*}{0} & \multirow{2}{*}{0} & \multirow{2}{*}{0} \\
\hline & 2 & - & & & & & & \\
\hline \multirow{2}{*}{3} & 1 & 363525 & \multirow{2}{*}{2} & \multirow{2}{*}{4} & \multirow{2}{*}{$\delta_{k}$} & \multirow{2}{*}{0} & \multirow{2}{*}{0} & \multirow{2}{*}{0.195} \\
\hline & 2 & 293525 & & & & & & \\
\hline \multirow{2}{*}{4} & 1 & 233814.382 & \multirow{2}{*}{2} & \multirow{2}{*}{2} & \multirow{2}{*}{$\lambda_{k}$} & \multirow{2}{*}{1} & \multirow{2}{*}{1} & \multirow{2}{*}{0.805} \\
\hline & 2 & 50175 & & & & & & \\
\hline \multirow{2}{*}{5} & 1 & - & \multirow{2}{*}{ - } & \multirow{2}{*}{-} & \multirow{2}{*}{$y_{k}$} & \multirow{2}{*}{-699000} & \multirow{2}{*}{$4.1010 \mathrm{E}+9$} & \multirow{2}{*}{332290.42} \\
\hline & 2 & - & & & & & & \\
\hline \multirow{2}{*}{6} & 1 & 64835.150 & \multirow{2}{*}{2} & \multirow{2}{*}{2} & & \multirow{2}{*}{\multicolumn{2}{|c|}{$Z=0.381$}} & \\
\hline & 2 & 253525 & & & & & & \\
\hline
\end{tabular}
products 1 and 2, respectively.

All order allocation results and calculations for LAM and UAM are presented in Tables 2 and 3, respectively, according to which no value is allocated to suppliers 2 and 5. The utility value in UAM for the first and second objective functions is one, while there is a 0.195 deviation (deviation of $\mathrm{y}^{3}$ from $\mathrm{f}_{3 \min }$ for the third objective function). In the LAM, the utility is equal to 1 for the first function, but there is a 0.04 and 0.214 deviation for the second and third objective functions, respectively. As observed in Tables 3

Table 2. Results of order allocation for UAM model 
Table 3. Results of order allocation for LAM model

\begin{tabular}{|c|c|c|c|c|c|c|c|c|}
\hline Supplier(i) & Product(j) & $\begin{array}{l}\text { Order Quantity } \\
\qquad\left(\mathrm{m}^{2}\right)\end{array}$ & $\begin{array}{l}\text { Transportation } \\
\text { mode }\end{array}$ & $\begin{array}{l}\text { Number of trans- } \\
\text { portation mode }\end{array}$ & $\begin{array}{l}\text { Variables of } \\
\text { model }\end{array}$ & Ob. 1 & Ob. 2 & Ob. 3 \\
\hline \multirow{2}{*}{1} & 1 & 41026.42 & \multirow{2}{*}{1} & \multirow{2}{*}{2} & \multirow{2}{*}{$d^{-}$} & \multirow{2}{*}{0} & \multirow{2}{*}{0} & \multirow{2}{*}{0} \\
\hline & 2 & 193425 & & & & & & \\
\hline \multirow{2}{*}{2} & 1 & - & & & \multirow{2}{*}{$d^{+}$} & \multirow{2}{*}{0} & \multirow{2}{*}{0} & \multirow{2}{*}{0} \\
\hline & 2 & - & & & & & & \\
\hline \multirow{2}{*}{3} & 1 & 353425 & \multirow{2}{*}{2} & \multirow{2}{*}{4} & \multirow{2}{*}{$\delta_{k}$} & \multirow{2}{*}{0} & \multirow{2}{*}{0.04} & \multirow{2}{*}{0.214} \\
\hline & 2 & 283425 & & & & & & \\
\hline \multirow{2}{*}{4} & 1 & 218480.487 & \multirow{2}{*}{1} & \multirow{2}{*}{2} & \multirow{2}{*}{$\lambda_{k}$} & \multirow{2}{*}{1} & \multirow{2}{*}{0.96} & \multirow{2}{*}{0.768} \\
\hline & 2 & 78975 & & & & & & \\
\hline \multirow{2}{*}{5} & 1 & - & \multirow{2}{*}{-} & \multirow{2}{*}{-} & \multirow{2}{*}{$y_{k}$} & \multirow{2}{*}{-699000} & \multirow{2}{*}{$4.1896 \mathrm{E}+9$} & \multirow{2}{*}{335173.66} \\
\hline & 2 & - & & & & & & \\
\hline \multirow{2}{*}{6} & 1 & 83318.093 & \multirow{2}{*}{1} & \multirow{2}{*}{2} & & & \multirow{2}{*}{$z=0.495$} & \\
\hline & 2 & 243425 & & & & & & \\
\hline
\end{tabular}

and 4 , the value of $d_{k}^{+}$and $d_{k}^{-}$is zero for all three objective functions in both models. According to Equation 19, this means that the value of $y_{k}$ is equal to $f\left(x_{k}\right)$.

Figure 1 shows the difference in the results of the two models. According to this figure, the utility value of the three objective functions is in the range of $0.8-1$. In addition, the utility value for the first objective function is fully satisfied in both models. Moreover, as deduced from Figure 1, the rate of deviation from the utility for the third objective function (in both LAM and UAM) is higher than the other two objective functions.
In this section, the value of different parameters (e.g., optimistic-pessimistic degree $[\varepsilon]$, the level of possibility of fuzzy equality constraints $(\beta)$, and the total amount of fabric purchases $\left(\mathrm{N}_{\mathrm{j}}\right)$. Moreover, the results are recorded and their level of impact on the amount of textile order, transportation mode, number of means of transportation, and values of the objective function is reported. Tables 4 and 5, as well as Figures 2 and 3 show the effect of $\varepsilon$ and $\beta$ changes on utility value for each of the primary objective functions in the two models.

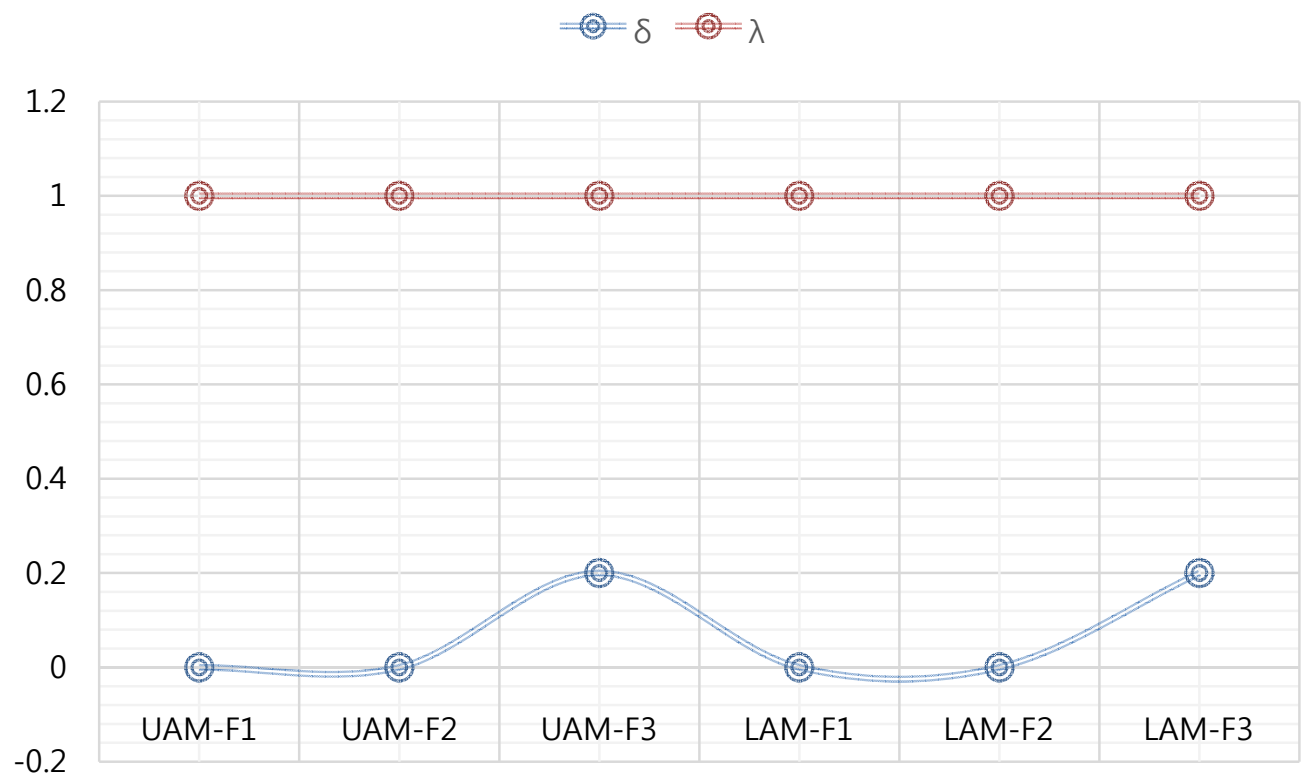

Figure 1. Utility value and deviation of $\delta_{k}$ for the three objective functions in both LAM and UAM. 
Table 4. Sensitivity analysis of $\varepsilon$ parameter

\begin{tabular}{ccccccc}
\hline & $\varepsilon=0$ & $\varepsilon=0.25$ & $\varepsilon=0.5$ & $\varepsilon=0.75$ & 1 & 1 \\
\hline UAM-F1 & 1 & 1 & 1 & 0.95 & 0.95 & 0.95 \\
\hline UAM-F2 & 0.97 & 0.96 & 1 & 1 & 0.98 \\
\hline UAM-F3 & 1 & 1 & 0.97 & 0.96 & 0.96 \\
\hline LAM-F1 & 1 & 0.97 & 0.95 & 0.95 & 0.95 \\
\hline LAM-F2 & 0.95 & 0.95 & 0.94 & 0.94 & 0.92 \\
\hline
\end{tabular}

Table 5. Sensitivity analysis of $\beta$ parameter

\begin{tabular}{ccccccc}
\hline & $\beta=0$ & $\beta=0.3$ & 0.6 & $\beta=0.8$ & 1 & 1 \\
\hline UAM-F1 & 1 & 1 & 1 & 0.92 & 0.91 & 0.91 \\
\hline UAM-F2 & 0.95 & 0.94 & 1 & 1 & 1 & 0.98 \\
\hline UAM-F3 & 1 & 1 & 1 & 0.9 & 0.98 \\
\hline LAM-F1 & 1 & 1 & 0.9 & 0.92 & 0.9 \\
\hline LAM-F2 & 0.94 & 0.96 & 0.93 & & 0.91 \\
\hline
\end{tabular}
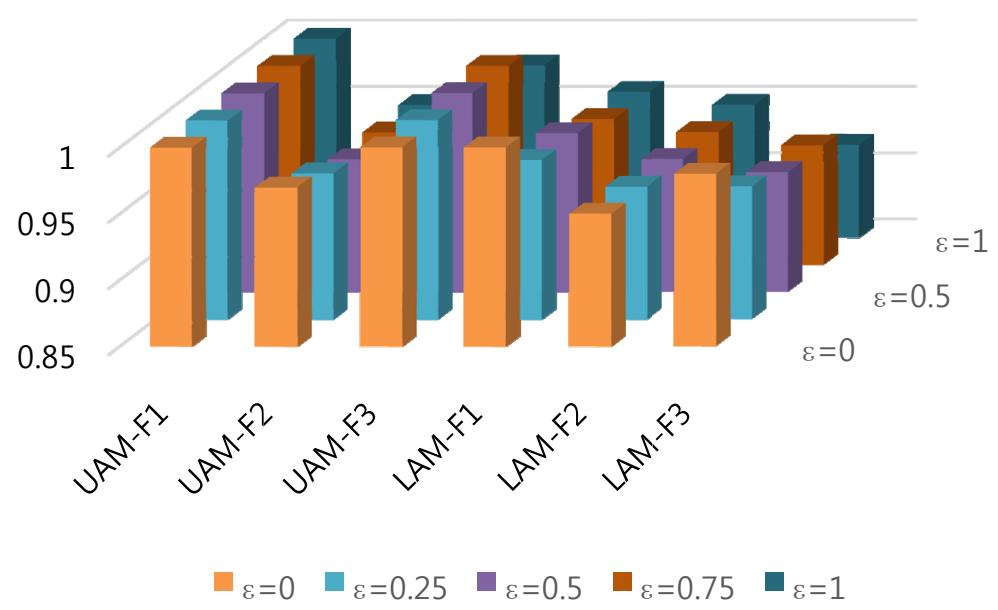

Figure 2. Effect of $\varepsilon$ changes on the utility value of LAM and UAM.

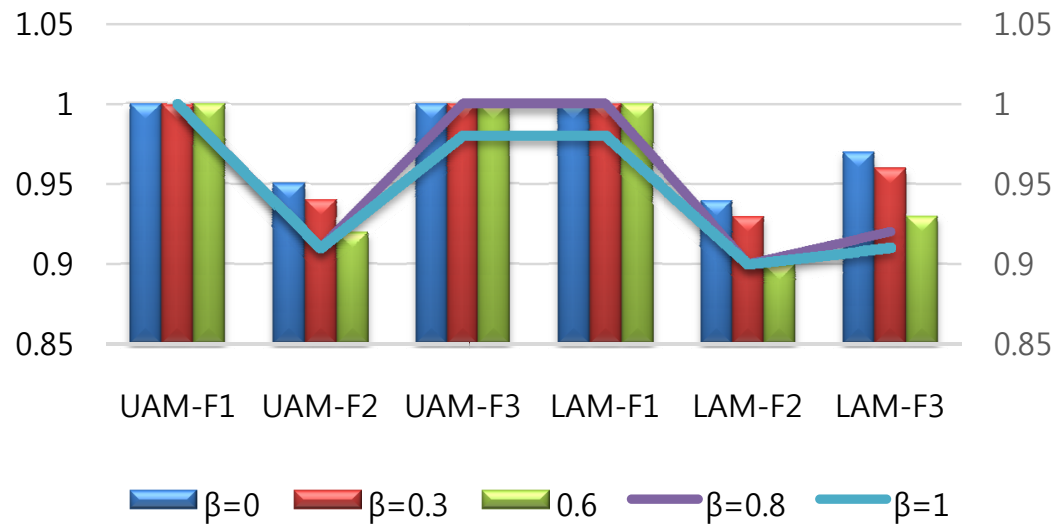

Figure 3. Effect of $\beta$ changes on the utility value of LAM and UAM. 
As observed in Figures 2 and 3, the utility value for objective function 1 (total purchase value) is usually equal to one in both models. There is no fuzzy parameter in the first objective function and the only effective factors are the amount of order and score of each supplier. The utility value of one means that the minimum amount of difference of this objective function and the $y_{k}$ value with the difference between the minimum and maximum value of the objective function is almost equal. On the other hand, the utility value for the third objective function (delayed products) is lower than other objective functions in both models, which means that the desired parameters only affected the utility value of the third objective function. According to the diagrams, it seems that most of the utility values for all three objective functions in the UAM are slightly higher than the LAM, which could be due to changes in the properties of the two models. On the other hand, as the amount of fabric purchased increases, the amount of the main objective function of ideal planning and the amount of the second objective function (cost) increases in the UAM. A decrease in the volume of the purchased business is evident when there is a decline in demand. This also leads to a decrease in costs. However, it may be the case that the volume of the business purchased is at a lower discount level due to the reduction in purchases, but at the same time is close to the upper limit of that discount level, which can increase costs. In addition, as the volume of purchases decreases, the number of suppliers selected to purchase decreases to three suppliers. Overall, increasing and decreasing the number of fabric purchases affects the number of means of transportation, the type of mode of transportation, the selected suppliers, and the cost. In LAM, as the amount of textile purchased increases, the amount of the main objective function and the amount of cost increase.

\section{CONCLUSION}

In this article, vendors offered different levels of discounts for further purchases, and there were a variety of transportation modes for shipping decisions. The expectation and chance-constrained definitive model was developed to solve the problem of uncertainty through integrating the ideal planning and flexible programming with mixed decision-makers' attitude after turning the multiobjective model into a single-objective model using multi-choice ideal planning. According to the results, the proposed model was sensitive to some parameters, including mixed decision-makers' attitude, a parameter related to fuzzy constraints, and the level of confidence defined by the decision-maker for less-than-equal constraints. In addition, the utility value increases with an increase in the optimistic grade. On the other hand, the utility value is fully satisfied for all three objective functions with the decrease of the parameter related to fuzzy inequality constraints in both UAM and LAM. The decision related to choosing a global source may include environmental and ethical guidelines set by the manufacturer, which may be an option for the future development of this approach. Furthermore, in the field of order allocation, other challenging issues such as random and price-dependent demand, cost and modes of transportation in intermediate distribution centers, exchange rate volatility, tax rates, and customs duties can be considered in modeling to determine the amount of purchase.

\section{REFERENCES}

Abdollahbeigi, M. and Asgari Bajgirani, M. (2020), Investigation of nitrogen removal in municipal wastewater treatment plants, Journal of Chemical Reviews, 2(4), 257-273.

Adhikari, A., Bisi, A., and Avittathur, B. (2020), Coordination mechanism, risk sharing, and risk aversion in a five-level textile supply chain under demand and supply uncertainty, European Journal of Operational Research, 282(1), 93-107.

Baghernejad, B. and Fiuzat, M. (2021), Application of ninhydrin as an efficient and novel catalyst for the preparation of 2-Amino-4H-Pyran derivatives, Journal Applied Organometallic Chemistry, 1(1), 17-21.

Ballou, R. H. (2004), Business Logistics/supply hain management: Planning, organizing and controlling supply chain (5th Ed.), Pearson/Prentice Hall Inc., New Jersey.

Barmasi, B. (2020), The effect of adding saccharin to the bath on the hardness and wear behavior of the coating, Journal of Engineering in Industrial Research, 1(2), 161-169.

Baskaran, V., Nachiappan, S., and Rahman, S. (2012), Indian textile supplier's sustainability evaluation using the gray approach, International Journal of Production Economics, 135(2), 647-658

Bonacich, E., Cheng, L., Chinchilla, N., Hamilton, N., and Ong, P. (1994), Global Production: The Apparel Industry in the Pacific Rim, Temple University Press, Philadelphia 19122, U.S.A.

Cadenas, J. M. and Verdegay, J. L. (1997), Using fuzzy numbers in linear programming, IEEE Transactions on Systems, Man, and Cybernetics, Part B (Cybernetics), 27(6), 1016-1022.

Çebi, F. and Otay, İ. (2016), A two-stage fuzzy approach for supplier evaluation and order allocation problem with quantity discounts and lead time, Information Sciences, 339, 143-157.

Chan, F. T. S., Kumar, N., Tiwari, M. K., Lau, H. C. W., and Choy, K. L. (2008), Global supplier selection: A fuzzy AHP approach, International Journal of Pro- 
duction Research, 46(14), 3825-3857.

Chang, C. T. (2011), Multi-choice goal programming with utility functions, European Journal of Operational Research, 215(2), 439-445.

Demirtas, E. A. and Üstün, Ö. (2008), An integrated multiobjective decision making process for supplier selection and order allocation, International Journal of Management Sience, Omega, 36(1), 76-90.

Díaz-Madroñero, M., Mula, J., and Peidro, D. (2017), A mathemathical programming model for integrating production and procurement transport decision, $A p$ plied Mathematical Modelling, 52, 527-543.

Díaz-Madroñero, M., Peidro, D., and Mula, J. (2014), A fuzzy optimization approach for procurement transport operational planning in an automobile supply chain, Applied Mathematical Modelling, 38(23), 5705-5725.

Ghasemy Yaghin, R., Fatemi Ghomi, S. M. T., and Torabi, S. A. (2015), A hybrid credibility-based fuzzy multiple objective optimisation to differential pricing and inventory policies with arbitrage consideration, International Journal of Systems Science, 46(14), 2628-2639.

Ghasemy Yaghin, R., Fatemi Ghomi, S. M. T., and Torabi, S. A. (2013), A possibilistic multiple objective pricing and lot-sizing model with multiple demand classes, Fuzzy Sets and Systems, 231, 26-44.

Ghodsypour, S. H. and O'Brien, C. (2001), The total cost of logistics in supplier selection, under conditions of multiple sourcing, multiple criteria and capacity constraint, International Journal Production Economics, 73(1), 15-27.

Ghorbani, M., Bahrami, M., and Arabzad, S. M. (2012), An integrated model for supplier selection and order allocation; using Shannon entropy, SWOT and linear programming, international conference on leadership, technology and innovation management, ProcediaSocial and Behavioral Sciences, 41, 521-527.

Hamdan, S. and Cheaitou, A. (2016), Supplier selection and order allocation with green criteria: An MCDM and multi-objective optimization approach, Computers and Operation Research, 81, 282-304.

Hammami, R., Temponi, C., and Frein, Y. (2014), A scenario-based stochastic model for supplier selection in global context with multiple buyers, currency fluctuation uncertainties, and price discounts, European Journal of Operational Research, 233(1), 159-170.

$\mathrm{Hu}, \mathrm{X}$. and Motwani, J. G. (2013), Minimizing downside risks for global sourcing under price-sensitive stochastic demand, exchange rate uncertainties, and supplier capacity constraints, International Journal of Production Economics, 147, 398-409.

Keskin, B. B., Üster, H., and Çetinkay, S. (2010), Integration of strategic and tactical decisions for vendor selection under capacity constraints, Computers \& Op- erations Research, 37(12), 2182-2191.

Kim, S. (2012), Global sourcing of South Korean apparel industry: Sourcing trend and supplier selection, The Journal of the Textile Institute, 103(12), 1335-1351.

Koprulu, A. and Albayrakoglu, M. M. (2017), Supply chain management in the textile industry: A supplier selection model with the analytical hierarchy process, ISAHP 2007, Viña Del Mar, Chile.

Kumar, M., Vrat, P., and Shankar, R. (2004), A fuzzy goal programming approach for vendor selection problem in a supply chain, Computers \& Industrial Engineering, 46(1), 69-85.

Kumar, P., Shankar, R., and Yadav, S. S. (2011), Global supplier selection and order allocation using FQFD and MOLP, International Journal of Logistics Systems and Management, 9(1), 43-68.

Musau, E. G. (2021), Towards a sustainable horticultural value chain among smallholder farmers in Kenya: unlocking the potential of mobile telephone, African Journal of Education, Science and Technology, 6(2), 128-140.

Nayak, R. and Padhye, R. (2015), Garment Manufacturing Technology, Woodhead Publishing, The Textile Institute.

Parra, M. A., Bilbao Terol, A. B., Pérez Gladish, B., and Rodríguez Uría, M. V. (2005), Solving a multiobjective possibilistic problem through compromise programming, European Journal of Operational Research, 164(3), 748-759.

Pazhani, S., Ventura, J. A., and Mendoza, A. (2016), A serial inventory system with supplier selection and order quantity allocation considering transportation costs, Applied Mathematical Modelling, 40(1), 612634.

Prasanna Venkatesan, S. and Goh, M. (2016), Multiobjective supplier selection and order allocation under disruption risk, Transportation Research Part E: Logistics and Transportation Review, 95, 124-142.

Razmi, J., Songhori, M. J., and Khakbaz, M. H. (2009), An integrated fuzzy group decision making/fuzzy linear programming (FGDMLP) framework for supplier evaluation and order allocation, International Journal of Advanced Manufacturing Technology, 43, 590-607.

Songhori, M. J., Tavana, M., Azadeh, A., and Khakbaz, M. H. (2011), A supplier selection and order allocation model with multiple transportation alternatives, International Journal of Advanced Manufacturing Technology, 52, 365-376.

Su, J., Gargeya, B., and Richter, S. J. (2005), Global sourcing shifts in the U.S. textile and apparel industry: A cluster analysis, The Journal of the Textile Institute, 96(4), 261-276.

Teng, S. G. and Jaramillo, H. (2005), A model for evaluation and selection of suppliers in global textile and 
apparel supply chains, International Journal of Physical Distribution \& Logistics Management, 35 (7), 503-523.

Torabi, S. A. and Hassini, E. (2009), Multi-site production planning integrating procurement and distribution plans in multi-echelon supply chains: An interactive fuzzy goal programming approach, International Journal of Production Research, 47(19), 54755499.

Xia, W. and Wu, Z. (2007), Supplier selection with multiple criteriain volume discount environments, Omega, 35(5), 494-504.
Zhalechian, M., Tavakkoli-Moghaddam, R., Rahimi, Y., and Jolai, F. (2017), An interactive possibilistic programming approach for a multi-objective hub location problem: Economic and Environmental design, Applied Soft Computing, 52, 699-713.

Dr. Roy Setiawan is currently working as Assistant professor at Department of Management, Universitas Kristen Petra, Surabaya, Indonesia. He holds his $\mathrm{PhD}$ in Management from Universitas Airlangga, Surabaya, Jawa Timur, Indonesia. His expertise are in Human Resources, Leadership, and Management. 